\title{
КОНКУРЕНТОСПОСОБНОСТЬ ПРЕДПРИЯТИЙ
} И BНEШHНME МАКРОЭКОНОМИИЕСКИЕ РИСКИ

Аннотация. Логистические системы предприятий наряду с другими компонентами определяют уровень конкурентоспособности субъектов хозяйствования. Однако часто расчеты уровня рисков в таких системах ограничиваются только эндогенными факторами. В статье предлагается учитывать ряд внешних воздействий, определяющих бизнес-среду региона, отрасли. Заложены теоретические принципы авторской методики оценки рисков с учетом экзогенных факторов.

Ключевые слова: конкурентоспособность, экзогенный фактор риска, логистическая система, методика оченки риска, распределенный эффект.

Для цитирования: Зенькова Л., Шишко Е. Конкурентоспособность предприятий и внешние макроэкономические риски // Наука и инновачии. 2020. № 7. С. 61-65. https://doi.org/10.29235/1818-9857-2020-7-61-65.

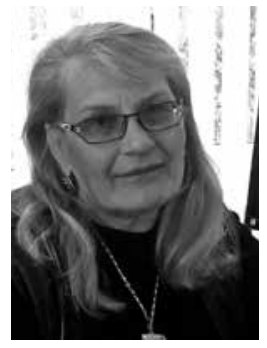

Лариса Зенькова, профессор кафедры экономики и управления БГЭУ, доктор экономических наук, доцент

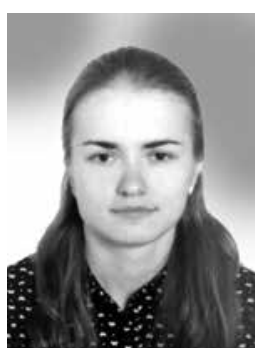

Елена Шишко, аспирант кафедры экономики и управления БГэу

Создаваемые логистические цепи напрямую влияют на издержки предприятия, а значит, на его конкурентоспособность и величину ожидаемой прибыли. Однако эффективность логистики в значительной степени определяется не только обретением выгодных партнеров по поставкам и сбыту, мероприятиями продвижения товара на рынок и послепокупочным сервисом, но и способностью упреждения и сведения к минимуму внешних рисков. К их категории относятся макроэкономические условия, на которые сложно оказывать непосредственное воздействие. В рыночной хозяйственной среде предприятия функционируют в условиях неполноты информации и неопределенности протекания экономических процессов. Из этого следует, что при принятии управленческих решений необходимо учитывать существующие риски и то, что их наличие при ведении деятельности предполагает не только опасность, но и возможность получения прибыли (выгод), а сам процесс требует соответствующих специальных знаний и навыков.

На основе критического анализа и обобщения исследований в профильной области [1-6]) можно определить риск как некую ситуацию (событие), наступление которой способно привести к негативным последствиям, например, убыткам или сбоям в технике, и в то же время к положительному воздействию, например дополнительному доходу. Исходя из известных исследований теории рисков, можно выделить их основные черты: противоречивость, альтернативность и неопределенность. Первое из перечисленных качеств возникает в связи со столкновением объективно существующих рискованных действий с субъективной оценкой их будущих результатов.

Согласно проведенному авторами анализу, следует дифференцированно рассматривать возможные последствия полностью неконтролируемых 


\begin{tabular}{|c|c|c|}
\hline $\begin{array}{l}\text { Знаком «-» отмечены позиции, } \\
\text { которые авторы не включили в перечень рисков }\end{array}$ & $\begin{array}{l}\text { Датченко } \\
\text { А.А. }\end{array}$ & $\begin{array}{l}\text { Карпова } \\
\text { Н.П. }\end{array}$ \\
\hline 1.Безопасность производства & + & - \\
\hline 1.1 Безопасность сырья: & + & - \\
\hline чистота & + & - \\
\hline свежесть & + & - \\
\hline 1.2 Безопасность оборудования: & + & - \\
\hline исправность & + & - \\
\hline санитарное состояние & + & - \\
\hline 1.3 Персонал: & + & - \\
\hline квалификация & + & - \\
\hline ответственность & + & - \\
\hline безопасность технологического процесса: & + & - \\
\hline экологичность & - & - \\
\hline бесперебойность & + & - \\
\hline 2. Безопасность транспортировки & + & - \\
\hline 2.1. Техническое состояние транспорта: & + & - \\
\hline исправность & + & - \\
\hline своевременность обслуживания & + & - \\
\hline 2.2. Условия транспортирования: & + & - \\
\hline условия погрузночно-разгрузочных работ & + & - \\
\hline способ укладки в транспортном средстве & + & - \\
\hline физико-химические свойства груза & + & - \\
\hline объемно-массовые показатели перевозки & + & - \\
\hline режим хранения груза в пути & + & - \\
\hline экологичность транспорта & - & - \\
\hline 2.3. Сроки поставки, транспортировки & + & + \\
\hline ремонтные работы на дорогах & + & + \\
\hline дтп & + & + \\
\hline скорость движения & + & + \\
\hline пробки & + & + \\
\hline 2.4. Погодные условия & + & - \\
\hline 3. Безопасность реализации продукции & + & - \\
\hline 3.1. Условия реализации: & + & - \\
\hline наличие комплекта униформы, соответствующей бренду & + & - \\
\hline размещение и укладка продуктов в холодильное хранение & + & - \\
\hline принципы товарного соседства & + & - \\
\hline 3.2. Режим и условия хранения в торговом зале: & + & - \\
\hline риск недоброкачественности поступивших продуктов & + & + \\
\hline температура & + & - \\
\hline циркуляция воздуха, вентиляция & + & - \\
\hline 3.3. Сансостояние помещения, торгового оборудования, инвентаря: & + & - \\
\hline частота дезинфекции & + & - \\
\hline качество уборки & + & - \\
\hline 3.4. Персонал: & + & - \\
\hline квалификация & + & - \\
\hline ответственность & + & - \\
\hline 4. Безопасность послепокупочного сервиса: & - & \\
\hline квалификация наладчиков и ремонтников & - & - \\
\hline безопасность инструментов & - & - \\
\hline 5. Кредитные риски & - & + \\
\hline 6. Валютные риски & - & + \\
\hline
\end{tabular}

Таблица 1. Компоненты рисков логистических систем согласно разным авторским методикам. Источник: разработано на основе [7-8] и частично контролируемых факторов возникновения рисков (в разрезе внутренних и внешних). К первым можно отнести социальные, научно-технические, природные факторы и государственные меры регулирования деятельности в сфере законодательства, а к частично контролируемым - неопределенность на рынках поставщиков, потребителей и конкурентов, а также внешние макроэкономические риски. Поскольку последние нельзя определить и предсказать полностью, а лишь с какой-то долей вероятности, в этих же пределах их можно учитывать в хозяйственной деятельности предприятий региона. Посредством количественного измерения, вероятностного прогнозирования величины риска и выделения сфер его повышенного влияния возможно в ограниченной степени управлять рисками, укрепляя тем самым конкурентные позиции своей компании.

Среди основных внешних макроэкономических рисков в Республике Беларусь, на наш взгляд, наиболее показательны и статистически фиксируемы следующие:

- доля инвестиций в основной капитал от ВВП,\%;

- налоговая нагрузка на экономику,\%;

- кониентрация производства и капитала в определенной сбере экономики;

- уровень инбляиии (\% роста иен);

- колебания валютного курса;

- валовой внешний долг к ВВП,\%; В международной практике также ведутся расчеты уровней рисков для предпринимательства, связанные с эффективностью функционирования институтов (прежде всего госаппарата и Национального банка), стабильностью финансовой системы 
страны, социальной сферы, развитостью инфраструктуры, устойчивостью рыночных связей. В частности, речь идет об Индексе глобальной конкурентоспособности, глобальном инновационном индексе, оценивающем, кроме того, еще человеческий капитал, интенсивность научных исследований, результаты творческих изысканий, Индексе ведения бизнеса. Однако из-за недостатка информации в динамике по их расчетным компонентам представляется затруднительным использовать оные для белорусских организаций.

На текущий момент в отечественной науке имеется несколько методик оценки рисков для логистических цепей предприятий (табл. 1). Их подробный сравнительный анализ указывает на слишком узкий спектр выбранных для учета внешних факторов по сравнению с перечнем, предложенным в данной статье. Как правило, кластеры рисков построены исходя из поэтапного продвижения товара по логистическим звеньям и вообще не учитывают эффективное функционирование институтов экономики, инфляцию, инвестиционную активность, бремя внешнего долга и налоговой нагрузки (влияющих на величину совокупного платежеспособного спроса в стране), уровень концентрации капитала, а значит, степени жесткости конкурентной борьбы на рынках.

Принципиальный поворот методик оценки внешних рисков в логистических цепях к макроэкономическим факторам полностью изменит значение рисков для субъектов разных регионов и отраслей, позволит реально выявить преимущества развития тех или иных производств в специфических условиях. Для определения конкурентоспособности предприятия (и даже региона в целом) и эффективности их логистического моделирования возможно создание системы оценки в виде корректирующих коэффициентов внешних рисков по отношению к ожидаемой прибыли.

Макроэкономические риски связаны прежде всего с уровнем налогообложения и его изменчивостью. Анализ этого фактора по ежемесячным статистическим данным для Республики Беларусь за период 2011-2018 гг. показывает, что риски, связанные с чрезмерностью налоговой нагрузки на экономику, уменьшаются по мере продвижения к 2018 году. Но поскольку среди субъектов экономики сложились высокие инфляционные ожидания, воздействие этого фактора на конкурентные позиции фирмы очень высоки. В таких условиях частные сбережения в большей степени уходят на покупку инвалюты, чем на приобретение продукции фирмы. Возрастают риски неполной реализации товара. А значит, учет
Годы 201120122013201420152016201720182019 Налоговое бремя, \% $23,9 \quad 25,2 \quad 24,6 \quad 23,5 \quad 24,8 \quad 25,1 \quad 25,0 \quad 25,9 \quad 25,8$

Таблица 2. Доля налоговых доходов консолидированного бюджета в ВВП Республики Беларусь, \%. Источник: рассчитано по [10-14]

этого фактора необходим при оценке риска. Мы не претендуем на абсолютную верность и окончательность варианта коррекции методики, однако предлагаем следующее.

Введем условное обозначение Кн, отражающее уровень влияния налогового бремени на ожидаемую прибыль фирмы (коэффициент налогового риска). Значение Кн рассчитывается исходя из превышения фактического значения налогового бремени над оптимальным, сложившимся в годы после мирового финансового кризиса (табл. 2, графба 2011 г.). В результате за 2019 г. превышение составило $8 \%$ $(25,9: 23,9=1,08)$. Следовательно, ожидаемую прибыль следует скорректировать в сторону понижения на $8 \%$.

Не только само налоговое бремя, но и частота изменения системы налогообложения также является экзогенным макроэкономическим риском для фирмы. В связи с этим представляется возможным использование коэффициента Кз, отражающего степень «подвижности» экономического законодательства и либеральность правительства в сфере предпринимательства. Возникает проблема его оценки. Наиболее оптимально, на наш взгляд, воспользоваться рассчитываемым экспертным методом и уже известным в международной практике индексом ведения бизнеса. Для этого сопоставляют значение ИВБ текущего года с базовым, 2011 г. В нашем случае корректирующий прибыль коэффициент будет значительным: ожидаемую маржинальность надо увеличить на $66,4 \%(37: 110=33,6 \% ; 100-33,6=66,4 \%)$. Однако, к сожалению, ряд факторов «работает» в сторону усиления рисков и снижения конкурентоспособности и ожидаемой прибыли (табл. 3).

Эффективность созданных предприятием логистических цепей зависит не только от найденных в текущий период наименьших затрат на поставку и сбыт товара среди возможных вариантов партнерских соглашений, но и от долгосрочных

\begin{tabular}{l|c|c|c|c|c|c|c|c|c} 
Годы & 2011 & 2012 & 2013 & 2014 & 2015 & 2016 & 2017 & 2018 & 2019 \\
$\begin{array}{l}\text { Индекс } \\
\text { ведения } \\
\text { бизнеса/ } \\
\begin{array}{l}\text { место } \\
\text { страны }\end{array}\end{array}$ & 110 & 37 & 38 & 57 & 43 & 50 & 63 & 38 & 37 \\
\hline
\end{tabular}

Таблица 3. Динамика индекса ведения бизнеса (ИВБ) и место Республики Беларусь за период 2011-2019 гг. Источник: [15, 16] 


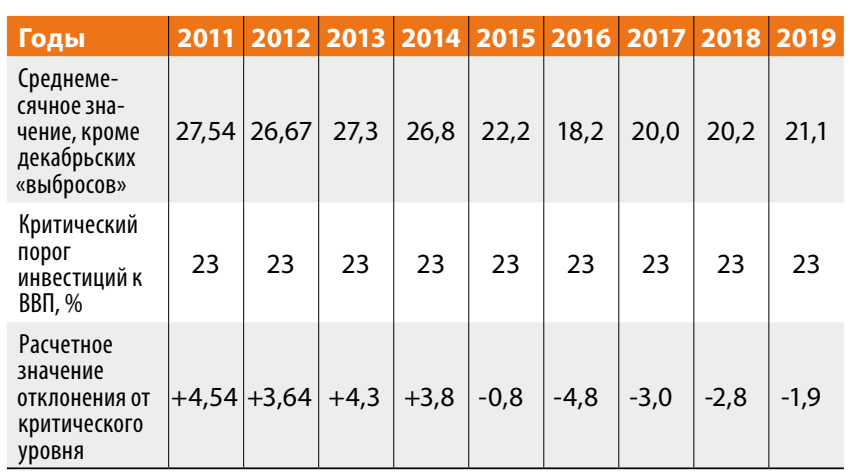

Таблица 4. Динамика удельного веса инвестиций в основной капитал в объеме ВВП Республики Беларусь за период 2011-2019 гг., \%. Источник:разработано на основе данных Управления статистики инвестиций и строительства Национального статистического комитета Республики Беларусь и [9-11]

инвестиционных стратегий организаций - звеньев таких цепей. Следовательно, оценка уровня инвестиционной безопасности в регионе способствует пониманию возможных рисков будущих провалов в выстроенных оптимальных логистических схемах. Соотношение фактических вложений в основной капитал к ВВП (или ВРП) (23\%) отражает уровень инвестиционной безопасности и является риском внешнего макроэкономического характера для региона, в котором располагается субъект хозяйствования. Оно показывает интенсивность модернизации общественного производства, степень привлекательности экономического пространства страны для инвестиций, в том числе иностранных. Следовательно, для предприятия оно является сигналом будущей конкурентоспособности региона.

Введем условное обозначение величины индекса инвестиционного макроэкономического внешнего риска Ки, отражающего уровень инвестиционной безопасности в экономике. Фактическое значение доли инвестиций от ВВП широко известно и статистически фиксируемо. Величину Ки следует, таким образом, оценивать исходя из среднего отклонения фактического значения параметра от критического (табл. 4). За период 2011-2019 гг. отклонение Ки составило $-0,33 \%$, что потребует корректировки ожидаемой прибыли в сторону понижения из-за риска устойчивой тенденции падения инвестиционной привлекательности региона.

С целью выявления влияния на логистические системы региона такого риск-фактора как жесткость конкурентного противостояния производителей на рынке (с помощью уровня концентрации производства) используем обозначение - коэффициент Кк. Нами произведен его расчет для одной отрасли - промышленности на основе применяемой в мировой практике формулы индекса монопольной власти Н-индекса (Херфиндаля-Хиршмана):

$H=S_{1}^{2}+S_{2}^{2}+\ldots+S_{n}^{2}$

где $S i$ - доля $i$-той фирмы в общем объеме выпуска отрасли.

Максимальное значение индекса Херфиндаля, таким образом, может быть 1,00 (или 1000\%). Чем выше Н-индекс, тем больше риск проигрыша для логистических систем в конкурентной борьбе на экономическом пространстве данной страны (региона). Замечено, что в предкризисные и кризисные периоды (2008, 2011, 2014-2015 гг.) значение этого показателя резко возрастает (рисунок). Такое явление возможно при двух обстоятельствах:

- сокращении общего количества предприятий, так как мелкие разоряются, на рынке остаются фирмы с крупными капиталами и масштабами производства;

- сохранении зарегистрированных субъектов хозяйствования при значительном падении объемов производства мелких фирм из-за финансовых затруднений.

Значимым фактором риска при построении конкурентоспособных логистических систем является колеблемость цен (инфляции) на протяжении изучаемого периода. Причем для логистов важна инфляция, рассчитанная по всем сферам экономики, а не только в розничной продаже или, например, в сельском хозяйстве. В связи с этим наиболее репрезентативным показателем для расчета коэффициента инфляционного риска (Кц) представляются амплитуды колебаний дефлятора ВВП (табл. 5).

В связи с этим ожидаемую прибыль следует определять не одним числом, а «вилкой» между максимальным и минимальным значением, скорректи-

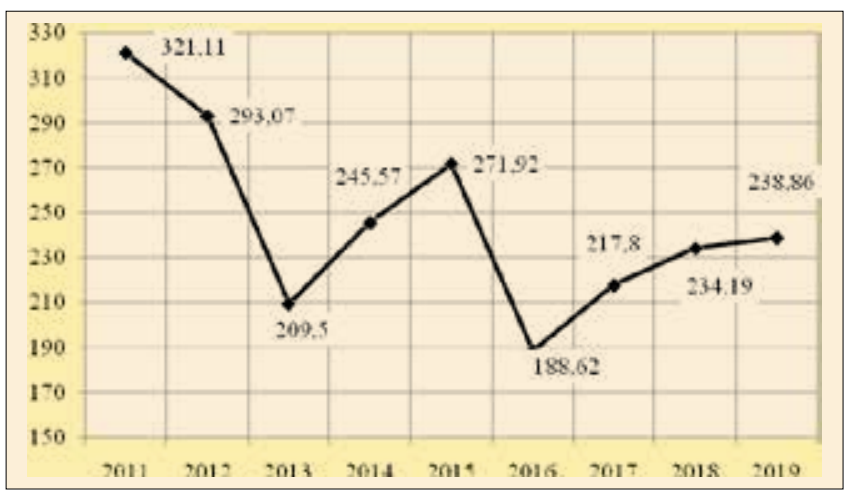

Рисунок. Динамика уровня концентрации промышленного производства в Республике Беларусь за период 2011-2019 гг. Источник: разработка Зеньковой Л.П. на основе данных Управления индексов промышленного производства Национального статистического комитета Республики Беларусь 


\begin{tabular}{|c|c|c|c|c|c|c|c|c|}
\hline Годы & 012 & 2013 & 2014 & 2015 & 2016 & 2017 & 2018 & 2019 \\
\hline 1-й КB & & 25,8 & 46,6 & 189,5 & 209,2 & 221,5 & 247,7 & 266,8 \\
\hline & & 129,1 & 48,4 & 182,6 & 197,6 & 212,2 & 247,7 & 266,7 \\
\hline & & & & 222,7 & & 260,6 & 309,9 & 278,8 \\
\hline & & 168,7 & 200,0 & 230,3 & 245,1 & 272,2 & 353,9 & \\
\hline көлеодниИ & 20,15 & 45,70 & 71,70 & $100, \angle 0$ & 123,40 & 41,63 & 106,2 & 12,0 \\
\hline
\end{tabular}

Таблица 5. Уровень инфляции и устойчивости цен в Республике Беларусь за период 2011-2017 гг. (к 1.01.2012 г.), \%.

Источник: разработано на основе [11-13] и данных Управления национальных счетов Национального статистического комитета Республики Беларусь

рованным на среднеарифметическую амплитуду инфляции за последние несколько лет (риск инфляции). Кроме того, в условиях чрезмерной открытости экономики и нарастающего внешнего долга важным фактором внешнего макроэкономического риска является сложившаяся стабильность валютного курса. Отмечается, однако, снижение его колебаний вокруг среднегодовых значений в периоды трех последних лет [10], что свидетельствует о росте эффективности монетарной политики, уменьшении рисков предприятий от внешнеэкономической деятельности, повышении их уверенности в ближайшем будущем и укреплении относительных конкурентных позиций. Аналогично в случае инфляции нижнюю и верхнюю границы ожидаемой прибыли следует корректировать на коэффициент риска Кв, представляющий собой сложившиеся амплитуды колебаний валютного курса за соответствующий период.

Таким образом, все предлагаемые в данной методике корректирующие индексы внешних рисков можно суммировать и использовать в дальнейшем как своеобразную совокупную процентную коррекцию ожидаемой прибыли.

Но и этого, по нашему мнению, недостаточно для совершенствования методик определения уровня рисков. Дело в том, что основные внешние макроэкономические риски не действуют одновременно и не сразу сказываются на работе предприятия. Им присущ так называемый временной профиль. Как правило, он размыт, распределен во времени и имеет скрытый, латентный период проявления. В таком случае, на наш взгляд, необходимо выявить «пик» действия последствий риска и адаптироваться именно к этому «пику», упреждая нежелательные процессы. С этой целью нами была исследована связь между фактором риска и результирующим показателем роста экономики на основе расчета коэффициента парной корреляции с лаговой объясняющей переменной. Выявлено, что наибольшие внешние макроэкономические риски пред- приятиям и регионам следует ожидать от уровня инфляции, колебаний валютного курса и практически без лага запаздывания. По остальным перечисленным внешним макроэкономическим рискам период пролонгированного действия фактора риска варьирует от 2 до 4 кварталов.

Таким образом, при формировании оптимальных логистических цепей предприятий в условиях высокой конкуренции необходимо, во-первых, включать в расчеты не только внутренние, но и внешние макроэкономические риски; во-вторых, опираться при этом на распределенное во времени воздействие рисковых факторов и учитывать латентный лаг запаздывания реакции.

- Summary. Logistics systems of enterprises, along with other components, determine the level of competitiveness of enterprises. However, very often calculations of the level of risks in logistics systems are limited only to endogenous factors. The article suggests taking into account a number of external risk factors that determine the business environment of the region and the industry. The theoretical principles of the author's methodology for assessing risks taking into account external factors are laid down.

- Keywords: competitiveness, exogenous risk factor, logistics system, risk assessment methodology, distributed effect.

https://doi.org/10.29235/1818-9857-2020-7-61-65

\section{СПИСОК ИСПОЛЬЗОВАННЫХ ИСТОЧНИКОВ}

1. Абчук В.А. Теория риска. - Л., 1983.

2. Балабанов И.Т. Риск-менеджмент. - М., 2008.

3. Богоявленский С.Б. Управление риском. - СПб., 2010.

4. Вишняков Я.Д., Радаев Н.Н. Общая теория рисков. -М., 2007.

5. Эллиотт М.У. Основы финансирования риска. -М., 2007.

6. Яхнеева И.В. Управление рисками в логистических системах и цепях поставок.Самара, 2012.

7. Датченко А.А. Оценка рисков в логистической системе товародвижения пищевой продукции // Вестник Ростовского гос экон ун-та. 2015. №1. С. 25-31.

8. Карпова Н.П. Оценка логистических рисков в процессе стратегического планирования снабжения организаций // Аудит и финансовый анализ. 2014. №2. С. 321-325.

9. Национальный статистический комитет Республики Беларусь // http://www.nbrb.by.

10. Статистический ежегодник Республика Беларусь 2019.- Минск, 2019.

11. Социально-экономическое положение Республики Беларусь в январе-декабре 2019 г.: статистический бюллетень Национального статистического комитета.Минск, 2019.

12. Статистический ежегодник Республика Беларусь 2018. - Минск, 2018.

13. Статистический ежегодник Республика Беларусь 2015.- Минск, 2015.

14. Статистический ежегодник Республика Беларусь 2012.- Минск, 2012.

15. Рейтинговые позиции Республики Беларусь в исследовании «Doing Business» // http://www.economy.gov.by/ru/doing_busines-ru/.

16. Рыбчинская А. В рейтинге сложности налоговой системы Беларусь оказалась хуже всех соседей // https://www.kp.by/daily/26688/3712671/.

17. Национальный банк Республики Беларусь // http://www.nbrb.by.

Статья поступила в редакцию 13.02.2020 г

드 SEE http://innosfera.by/2020/07/logistics_system 